\title{
Colapso de la red de drenaje y repercusiones urbanas en la zona costera de Acapulco, México, derivados de la tormenta tropical Manuel, 2013-2020
}

\section{Collapse of the drainage network and urban repercussions in the coastal area of Acapulco, Mexico, derived from tropical storm Manuel, 2013-2020}

Oscar Daniel Rivera González

Cursando el Doctorado en Urbanismo. Facultad de Arquitectura. Universidad Nacional Autónoma de México (UNAM). Circuito de los Posgrados S/N, C.U., Coyoacán, 04510 Ciudad de México, CDMX, México, oscardanieldanyboy@hotmail.com, ORCID https://orcid.org/0000-0002-7698-7433

Recibido: 2 de marzo 2020 || Aprobado: 17 de julio 2020

Resumen

El motivo de realizar el siguiente artículo de investigación, parte del objetivo de evidenciar y criticar la falta de estrategias en los procesos de gestión pública urbana llevadas a cabo por el Municipio de Acapulco, relacionadas con la infraestructura urbana y enfocadas con la saturación de la red de drenaje tras el paso de fenómenos hidrometeorológicos como lo acontecido después de la tormenta tropical Manuel, misma que impactó la zona costera de Acapulco en el año 2013, es por ello que se analizaron problemáticas ambientales-urbanas, mismas que se relacionan con afectaciones a la población, particularmente con el colapso de la red de drenaje, problemática que actualmente se sigue presentado en dicha zona costera, misma que deberá resolverse de manera inmediata, ya que la población se encuentra vulnerable debido al bajo nivel socioeconómico, lo cual afectará directamente a su grado de recuperación.

Palabras clave: Red de drenaje; Repercusiones urbanas; Tormenta tropical; Gestión pública

\section{Abstract}

The reason for carrying out the following research article, starts from the objective of evidencing and criticizing the lack of strategies in urban public management processes carried out by the Municipality of Acapulco, related to urban infrastructure and focused on network saturation drainage after the passage of Hydrometeorological Phenomena, such as what happened after Tropical Storm Manuel, the same that impacted the Acapulco Coastal Zone in 2013. For this, environmental-urban problems were analyzed, which are related to the affectations to the population, particularly with the collapse of the drainage network, a problem that is still present in this coastal area, which is the one that must be resolved immediately, because the population is vulnerable due to the low socioeconomic level, directly affecting their scale of recovery.

Key words: Drainage network; Urban repercussions; Tropical storm; Public Management

Cita sugerida: Rivera González, O.D. (2020). Colapso de la red de drenaje y repercusiones urbanas en la zona costera de Acapulco, México, derivados de la tormenta tropical Manuel 2013-2020. Estudios Socioterritoriales. Revista de Geografía, (28), 062. DOI: https:// doi.org/10.37838/unicen/est.28-062 


\section{INTRODUCCIÓN}

La República Mexicana y en específico el puerto de Acapulco tienen una gran problemática ante el impacto de fenómenos hidrometeorológicos, ya que en temporada de huracanes entre mayo y noviembre, la zona costera se ve en ocasiones afectada, impactando drásticamente dichos fenómenos generando diversas problemáticas (Mapa 1), por lo que este artículo pretende investigar la falta de una adecuada planeación urbana para la gestión del riesgo debido a la alta densidad de población, con la finalidad de prevenirlo y/o atenderlo eficientemente, lo cual permitirá proteger a los habitantes de esta región y a la infraestructura urbana de los mismos. Cabe mencionar que se realizó una indebida construcción de cadenas hoteleras sobre humedales, no propicios para la construcción, aunado a las problemáticas económicas, políticas y ambientales, tomando en cuenta la tormenta tropical Manuel, que posteriormente evolucionó a huracán dado su grado de devastación y por la velocidad de sus vientos, el cual es tema central en este artículo de investigación, mismo que fue uno de los más destructivos en la historia en cuanto a los impactos hidrometeorológicos en el caso de la zona costera de Acapulco, México.

Es importante explicar las diversas problemáticas del peligro que sufren algunas zonas costeras en el mundo tras el paso de un fenómeno hidrometeorológico

\footnotetext{
Por Riesgo vamos a entender cualquier fenómeno de origen natural o humano que signifique un cambio en el medio ambiente que ocupa una comunidad determinada que sea vulnerable a ese fenómeno. Por Vulnerabilidad vamos a denotar la incapacidad de una comunidad para "absorber", mediante el autoajuste, los efectos de un determinado cambio en su medio ambiente, o sea su "inflexibilidad" o incapacidad para adaptarse a ese cambio, que para la comunidad constituye, por las razones expuestas, un riesgo (...) Riesgo x Vulnerabilidad = Desastre. (Wilches Chaux, 1993, p. 17-18)
}

Con base en la cita anterior es de suma importancia puntualizar que la población mayormente afectada por fenómenos hidrometeorológicos es la que tiene ingresos económicos bajos y muy bajos, debido a esto, disminuye el grado de recuperación que puedan tener ante un hecho natural de tales magnitudes, es por ello que es muy complicado que puedan adaptarse y resistir este tipo de vulnerabilidad y peligro que sufren año con año, inclusive generando pérdidas de vidas humanas.

\footnotetext{
Esa vulnerabilidad se traduce en situaciones que debilitan a una comunidad para hacer frente a un agente perturbador, por ejemplo, entre los factores que incrementan la vulnerabilidad se encuentra la ubicación de viviendas en zonas inundables sin las debidas medidas de prevención, de viviendas cercanas a los cauces de arroyos y ríos, la falta de cumplimiento de los códigos locales de construcción, la poca organización comunitaria, la falta de preparación de las autoridades para informar, el actuar y hacer planes de protección frente a este tipo de situaciones, etc. (Rodríguez Esteves, 2017, p. 13)
}

Lo mencionado anteriormente se relaciona con el impacto hidrometeorológico que sin duda llegará a las zonas costeras en México, en específico a Acapulco. Es por ello que actualmente esta vulnerabilidad urbana crece con base en la geografía de terreno y condiciones climáticas, y afecta sin duda a las poblaciones más vulnerables socioeconómicamente. Con base en el urbanismo existente, en mayor medida sin una adecuada planeación, el Gobierno Mexicano se deberá ocupar en tratar de resarcir el daño con medidas de contención y mitigación ante este tipo de acontecimientos conocidos como huracanes, tormentas tropicales, ciclones tifones, entre otras denominaciones con base en el grado de devastación. 
Mapa 1. Impacto de ciclones tropicales en México 1970-2014 y las tres principales zonas de impacto (circunferencia roja)

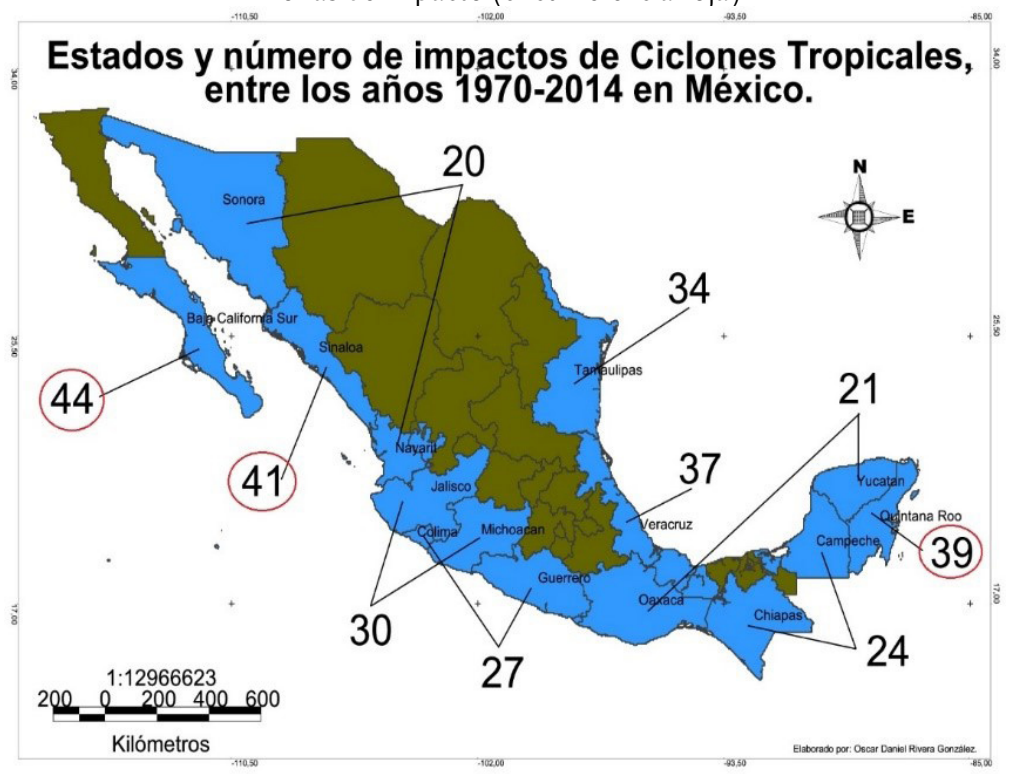

Fuente: Elaboración personal con base en datos de la Comisión Nacional del Agua (CONAGUA) y el Servicio Meteorológico Nacional (SMN). Software Sistema de Información Geográfica (SIG) gvSIG 2.1.0.2269

En el Mapa 2 se muestra la ubicación del área de estudio, iniciando en el Monumento Fuerte de San Diego y terminando en el Club de Golf Acapulco A.C (dirección oeste a este). El área es tomada en cuenta con base en la orografía y afectaciones a las colonias, las cuales se encuentran al norte de la zona costera de Acapulco.

Este fenómeno hidrometeorológico denominado Manuel, llamado también depresión tropical, tormenta tropical y huracán, dadas sus etapas de vida y su evolución, dejó serias afectaciones en parte del Estado de Guerrero y en zonas aledañas (Mapa 3).

Mapa 2. Zona costera de Acapulco y zona de estudio (del Monumento Fuerte de San Diego al Club de Golf Acapulco A.C) 2020

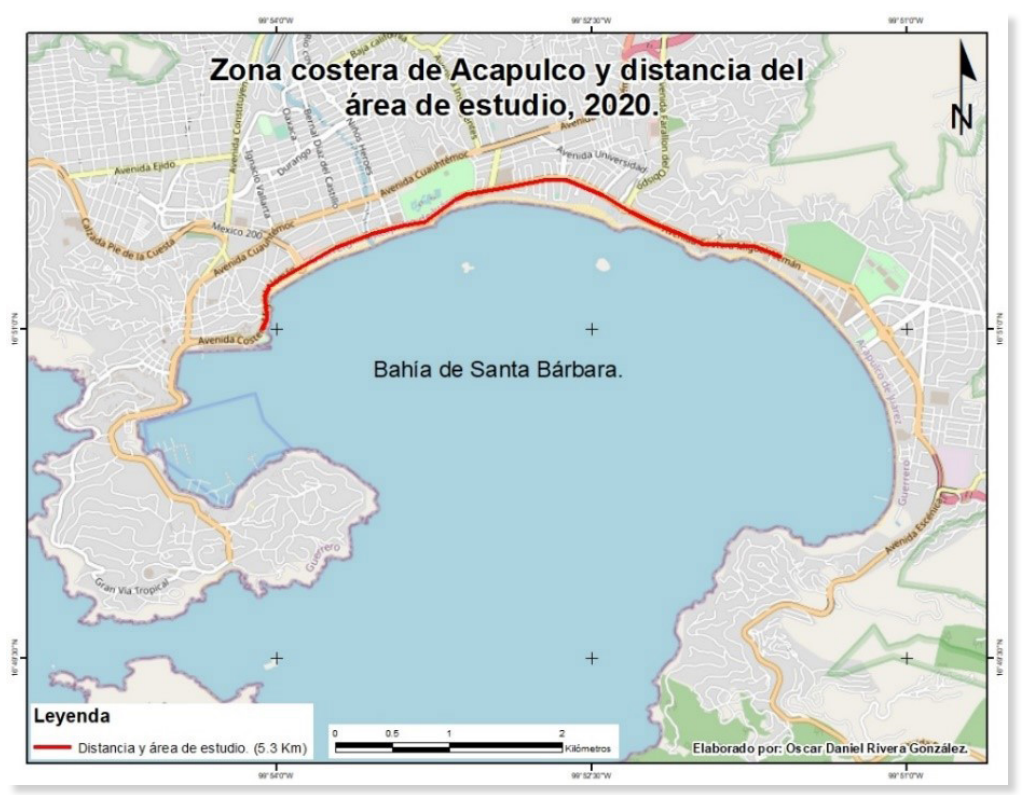

Fuente: elaboración personal con base en Software SIG ArcMap 10.3 
Mapa 3. Etapas y trayectoria del fenómeno hidrometeorológico Manuel en la zona costera de Acapulco. México 2013

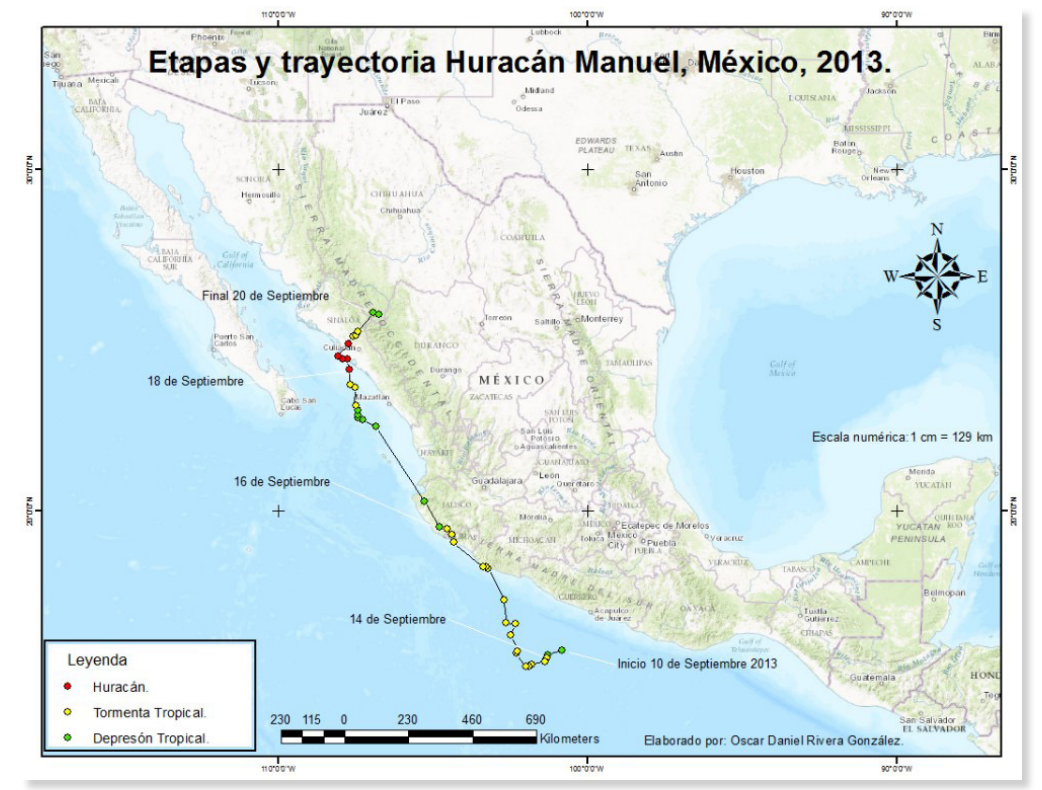

Fuente: elaboración personal con base en datos del Servicio Meteorológico Nacional (SMN) y Evaluación de Riesgos Naturales (ERN), Software SIG ArcMap 10.3.

El día 13 de septiembre por la mañana se generó la Depresión Tropical No. 13 del Océano Pacífico, la cual se formó a partir de una baja presión frente a la costa de Guerrero que, al encontrar condiciones favorables para su desarrollo, dio lugar a la Depresión Tropical 13 del Pacífico, la cual se inició a $170 \mathrm{~km}$ al suroeste de Técpan de Galeana, Guerrero, con vientos máximos sostenidos de $55 \mathrm{~km} / \mathrm{h}$, rachas de $75 \mathrm{~km} / \mathrm{h}$ y desplazamiento hacia el Noroeste a $6 \mathrm{~km} / \mathrm{h}$. Por la tarde, cuando se encontraba a $230 \mathrm{~km}$ al suroeste de Técpan de Galeana, la Depresión Tropical-13 se desarrolló a Tormenta Tropical Manuel con vientos máximos sostenidos de $75 \mathrm{~km} / \mathrm{h}$, rachas de $85 \mathrm{~km} / \mathrm{h}$ y desplazamiento hacia el oeste-noroeste a $9 \mathrm{~km} / \mathrm{h}$ (...) Durante el día 14 de septiembre la Tormenta tropical Manuel inició con un periodo estacionario y después enfiló su trayecto con rumbo hacia el norte, desplazándose en forma errática mientras aumentaba su fuerza frente a la costa de Guerrero y Michoacán, originando una amplia zona de nubosidad densa, cuya rotación favorecía la entrada importante de humedad hacia los estados del sur y occidente del país. (SMN, 2013, p. 1)

Lo anterior manifiesta las afectaciones a la zona costera de Acapulco en el Estado de Guerrero, ocasionando diversas problemáticas, en su infraestructura urbana, centrándonos en el colapso de la red de drenaje a lo largo de la zona denominada "Costera Miguel Alemán" (Mapa 2), derivó en graves problemáticas ambientales, políticas, sociales y económicas, afectando al turismo nacional e internacional en buena parte, el cual es un factor económico muy importante dado que de este viven muchos habitantes que se dedican al comercio turístico sobre la bahía. Dicho turismo visita el puerto por ser un lugar atractivo para pasar sus vacaciones, sin embargo las problemáticas en diferentes zonas del puerto de Acapulco originadas por estos fenómenos hidrometeorológicos en ocasiones reducen el número de visitantes.

"El huracán Manuel se originó el 13 de septiembre y se disipó el 20 de septiembre. El estado de Guerrero fue el más afectado pues en algunos sitios se presentaron lluvias acumuladas de hasta 650 mm" (ERN, 2013, p. 1). En cuanto a la acumulación de agua de origen pluvial, inclusive podría ser más elevando el nivel en años posteriores con base en futuros fenómenos hidrometeorolólogicos, por lo cual, el Gobierno Mexicano deberá 
tomar medidas urgentes de atención y prevención debido al alto riesgo que significa la caída y acumulación de agua, aunado a las rachas de vientos y el grado de urbanismo no regulado debido a los altos índices de densidad de población y marginación.

El alcalde de Acapulco, confirmó que existen unos 40,000 visitantes, nacionales y extranjeros, atrapados en hoteles y viviendas de segunda residencia en la zona Diamante, quienes no pueden salir por el nivel del agua de esa área que alcanza los 3.5 metros de altura. (Expansión, 2013, p. 1)

Por otro lado, cabe señalar que desde el año 1930 se realizaron diversas modificaciones al artículo 27 Constitucional fracción 3, en el cual se convierten grandes áreas de terrenos que originalmente eran de los ejidatarios a propiedad privada, agravándose aún más la problemática en el año 1992. Esto se asocia a la falta de una adecuada planeación y coordinación de las autoridades competentes en los tres niveles de Gobierno con los ciudadanos y el sector privado, resultando en serias afectaciones a la zona costera de la bahía de Acapulco, así como sus alrededores y en particular a la infraestructura urbana en cuanto a la red de drenaje, edificaciones, transporte, telecomunicaciones, energía eléctrica, etc.

El territorio físico sobre el que se asientan las ciudades y pueblos no es más que el resultado de la interacción entre los elementos inertes, los seres vivos y el clima. Pero ahora no nos vamos a preocupar nada más que del soporte físico sobre el que se asienta la urbanización. Es muy importante la evaluación cuidadosa de este soporte ya que, si no se hace correctamente, los costes ecológicos y económicos van a ser muy importantes. (Fariña, Fernández, Gálvez, Hernández y Urrutia, 2013, p. 25)

Lo anterior es fundamental para la planeación y organización urbana, ya que en caso de aumentar el grado de urbanismo no articulado y crecimiento del mismo en zonas de reserva natural o áreas naturales protegidas permitido por el aparato gubernamental, el resultado aumentará a devastaciones sociales y urbanas.

"La urbanización también provoca ciertos sistemas políticos y administrativos, disposiciones sociales, formas jurídicas, jerárquicas de poder, etc.” (Harvey, 2003, p. 371). En este caso se observa de manera muy marcada en México, ya que el crecimiento urbano no sería un problema si el grupo de colaboradores que toman decisiones importantes en cuanto al urbanismo, fueran autoridades competentes y capaces, sin embargo en la actualidad existen tantas problemáticas relacionadas y derivadas de las políticas públicas urbanas, así como la inadecuada toma de decisiones de nuestros representantes y al grado de corrupción e intereses personales, lo cual agrava aún más la problemática de vulnerabilidad en este caso afectando a la población originaria que se encuentra mayormente desprotegida.

\section{Metodología de estudio}

En el caso de la red de drenaje es importante señalar que hasta el año 1990 se habían realizado grandes trabajos en la zona costera de Acapulco y algunas partes de sus alrededores según la Comisión de Agua Potable y Alcantarillado del Municipio de Acapulco (CAPAMA), sin embargo según habitantes del puerto de Acapulco en la actualidad todavía existen tramos a lo largo de la Costera Miguel Alemán donde no existe red de drenaje, la cual colapsa y se inunda en temporada de huracanes al no poder drenar el agua. Por otro lado, los hoteles descargan directamente sus desechos y aguas negras al mar debido a la carencia de drenaje, inclusive no existen normas que regulen a estos hoteles o que se les multara por el descargue de sus aguas negras derivado de la inadecuada 
gestión en cuanto a la construcción y ampliación de la red de drenaje, complementando y reforzando esta información con la siguiente nota periodística:

Debido a que la avenida Miguel Alemán Valdés ya tiene 40 años, requiere mantenimiento mayor porque colapsará y nos podemos quedar sin costera desde Icacos a la Diana Cazadora, advirtió tajante el regidor presidente de la comisión de Servicios Públicos del cabildo porteño. Señaló que ya es tiempo de que se le haga justicia al puerto, porque nunca ha habido un apoyo real por parte del gobierno federal, sostuvo el edil. Alertó que el colapso de La Base es una mala señaló, desde hace 40 años no se ha cambiado la red de drenaje, le avisaron a la CAPAMA que había una fuerte fuga, fueron a ver y no había tubo de drenaje, ya desapareció, y así está toda la costera es el principio de un gran problema. (Enfoque, 2013, p. 1)

La CAPAMA no tiene la capacidad de atención suficiente de drenado, afectando a colonias y fraccionamientos como: Hornos, Parque Papagayo, Fracc. Magallanes, Adolfo López Mateos, Fracc. Farallón, Fracc. Condesa, Chinameca, Fracc. Villas Condesa, Bosques de Cañada, Cañada de los Amates, Jardín de los Amates, Cumbres de Figueroa, Unidad Habitacional Pablo Galeana, Fracc. Las Cumbres, Magisterio Guerrerense, Fracc. Las Cumbres, El Valle, Lomas de Magallanes, Unidad Habitacional CTM, Unidad Habitacional Farallón del Obispo, Unidad Habitacional Centro de Acapulco, Fracc. Farallón del Obispo, Del Valle, Garita de Juárez, La Laja, Unidad Habitacional Cuauhtémoc, Jacarandas, El Tigre, Fracc. El Roble, Bocamar, Unidad Habitacional El Tigre, Alianza, Fracc. Marroquín, Los Periodistas, Unidad Habitacional La Laja, Fracc. Leonardo Rodríguez Alcaine, Fracc. Las Anclas, Militar, Alta Progreso, Unidad Habitacional Hornos Insurgentes, 13 de Junio, 16 de Marzo, Unidad Habitacional Comisión Federal de Electricidad, Fracc. Real de Acapulco, Florida, Unidad Habitacional Florida, Progreso, Vista Alegre, Saturación Progreso Infonavit, Bellavista, Alta Bellavista, Morelos, Fuerte de San Diego, Alta Cuauhtémoc, Cuauhtémoc, Hogar Moderno, Carabalí Centro, Palmar de Carabalí, Barrio del Panteón, Acapulco de Juárez Centro y Barrio Petaquillas (Mapa 4).

Mapa 4. Bahía de Acapulco, principales colonias y fraccionamientos con mayor grado de afectación ante fenómenos hidrometeorológicos, 2020

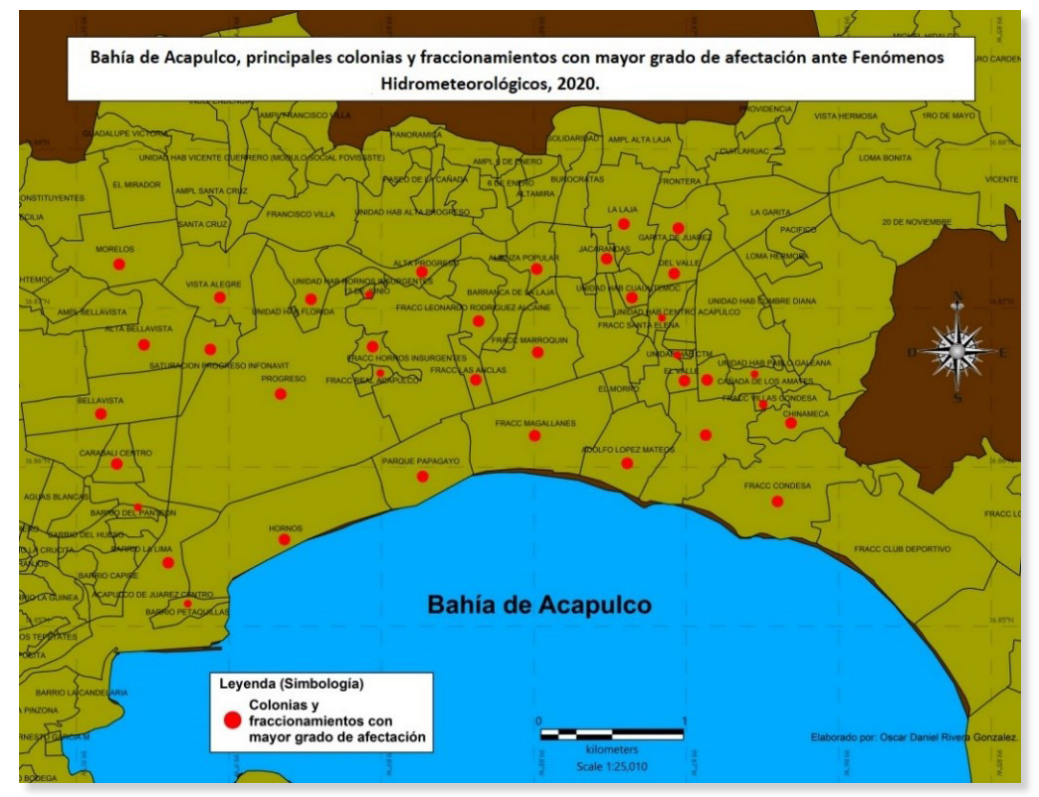

Fuente: elaboración personal con base en datos del Instituto Nacional de Estadística y Geografía (INEGI), Software SIG Maplnfo Pro 15.2 
En el Mapa 4 se pueden observar las colonias y fraccionamientos con mayor grado de vulnerabilidad por la afectación que se dio tras el paso de la tormenta tropical Manuel, con base en el grado de urbanización del lugar y densidad de población. Es importante mencionar que las colonias y fraccionamientos Bosques de Cañada, Jardín de los Amates, Cumbres de Figueroa, Fracc. Las Cumbres, Magisterio Guerrerense, Fracc. Las Cumbres, Lomas de Magallanes, Unidad Habitacional Farallón del Obispo, Fracc. Farallon del Obispo, El Tigre, Fracc. El Roble, Bocamar, Unidad Habitacional El Tigre, Los Periodistas, Unidad Habitacional La Laja, Militar, 16 de Marzo, Unidad Habitacional Comisión Federal de Electricidad, Florida, Fuerte de San Diego, Alta Cuauhtémoc, Cuauhtémoc, Hogar Moderno, Palmar de Carabali, no se observan en el mapa debido a la escala del mismo, sin embargo si se encuentran dentro del área de estudio.

La importancia del Mapa 5 estriba en la información obtenida con base en la muestra de la orografía y topografía medida en metros de la zona costera de Acapulco, ya que ante la llegada de un fenómeno hidrometeorológico propicia que las fuertes ráfagas de viento acompañadas de agua proveniente del Océano Pacífico se internen, provocando acumulación de esta agua de mar en las faldas y paredes de las montañas compuestas en su mayoría de basalto, ocasionando el acarreo de lodo, basura, residuos fecales, desechos de todo tipo a gran velocidad derivado de la pendiente tan pronunciada, colapsando la red de drenaje a lo largo de la avenida Miguel Alemán Valdés.

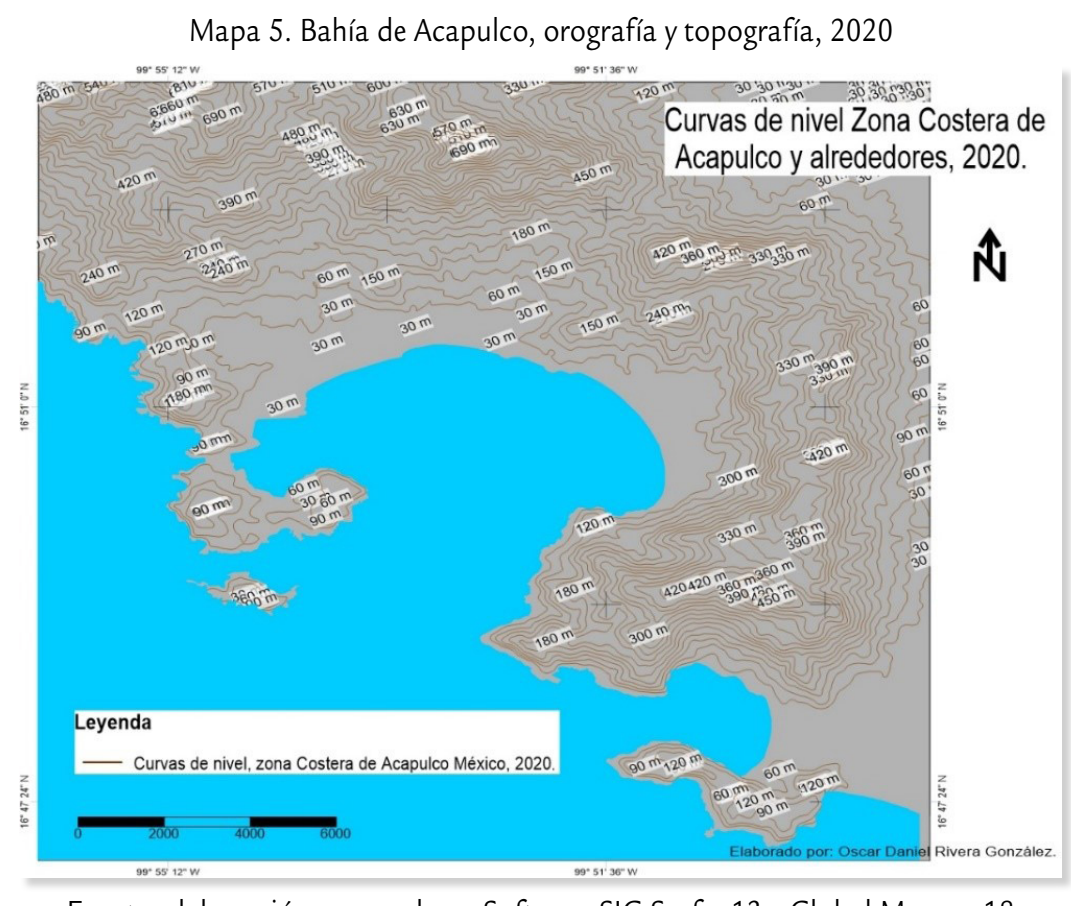

Fuente: elaboración personal con Software SIG Surfer 13 y Global Mapper 18

En la Imagen 1 se distingue el corte de terreno de sur a norte de la zona costera de Acapulco, con este perfil queda mejor entendida la altura en metros sobre el nivel del mar (m.s.n.m), que va de los 0 hasta los 939, por lo cual su punto más alto (de izquierda a derecha en la gráfica), dado por la orografía y topografía del lugar ante la llegada de un fenómeno hidrometeorológico, provoca el rebote de esta agua de mar en las faldas de la montaña y acarreo de materiales. 
Imagen 1. Perfil del terreno zona costera de Acapulco, imagen raster 3D (línea amarilla) y perfil del terreno representado en metros (gráfica línea roja)

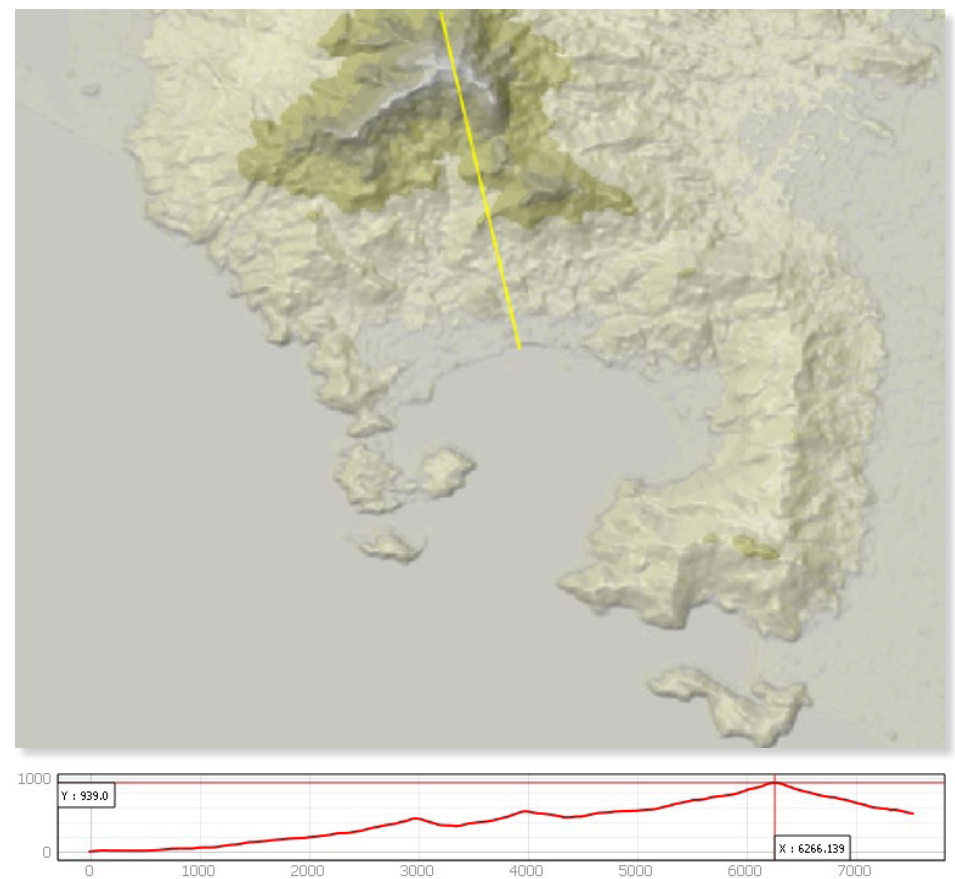

Fuente: elaboración personal con Software SIG QGIS 2.18.12.

El Mapa 6 muestra la hidrografía y zona urbana (color gris) al norte de la zona costera, observándose la distribución de los ríos, los cuales se activan y crecen en temporada de huracanes afectando a la mancha urbana, acarreando estos ríos todo tipo de materiales por su pendiente tan pronunciada terminando en la parte más baja de la costera.

Mapa 6. Hidrografía zona costera de Acapulco, INEGI subcuenca clave RH19Ac, longitud total de $122.88 \mathrm{~km}, 2020$

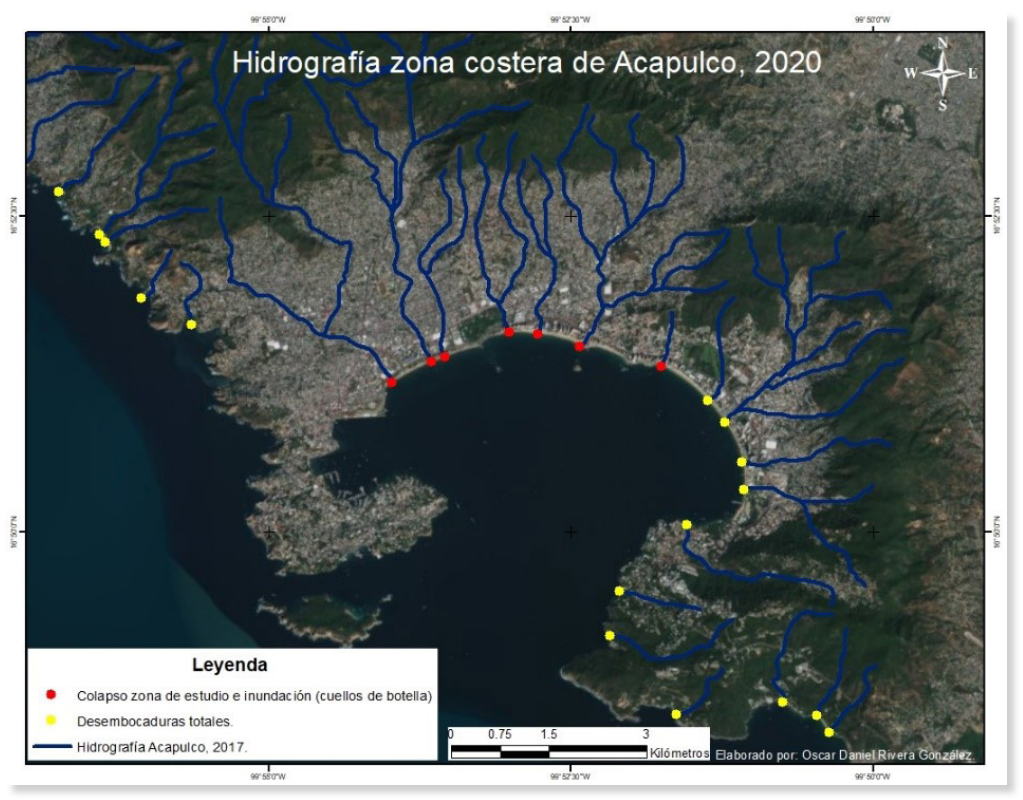

Fuente: elaboración personal con base en datos del Simulador de Flujos de agua de cuencas hidrográficas

(SIATL) del Instituto Nacional de Estadística y Geografía (INEGI), Software SIG ArcMap 10.3 
En el Mapa 7 se muestra la ubicación de los siete sectores en la zona costera de Acapulco catalogados por el Municipio y el Estado de Guerrero. Se debe poner atención en la zona 1, la cual, al ser la zona del Anfiteatro, carece en mayor parte de drenaje según habitantes del puerto y que al internarse cualquier fenómeno hidrometeorológico tierra adentro, acarrea todo tipo de residuos, inclusive fecales.

La zona del Anfiteatro, la cual abarca toda la zona costera de Acapulco, acarrea residuos fecales ya que la población que está asentada en esta parte en gran número no tiene red de drenaje, por lo cual hace sus necesidades sanitaras al aire libre. "La zona de anfiteatro se está poblando de nuevo; debido a la carencia de drenaje, ello aumenta el fecalismo al aire libre y el arrastre de residuos a la bahía" (Ramírez Sainz, 1989, p. 158).

Mapa 7. Ubicación de sectores en la zona costera de Acapulco, México 2020

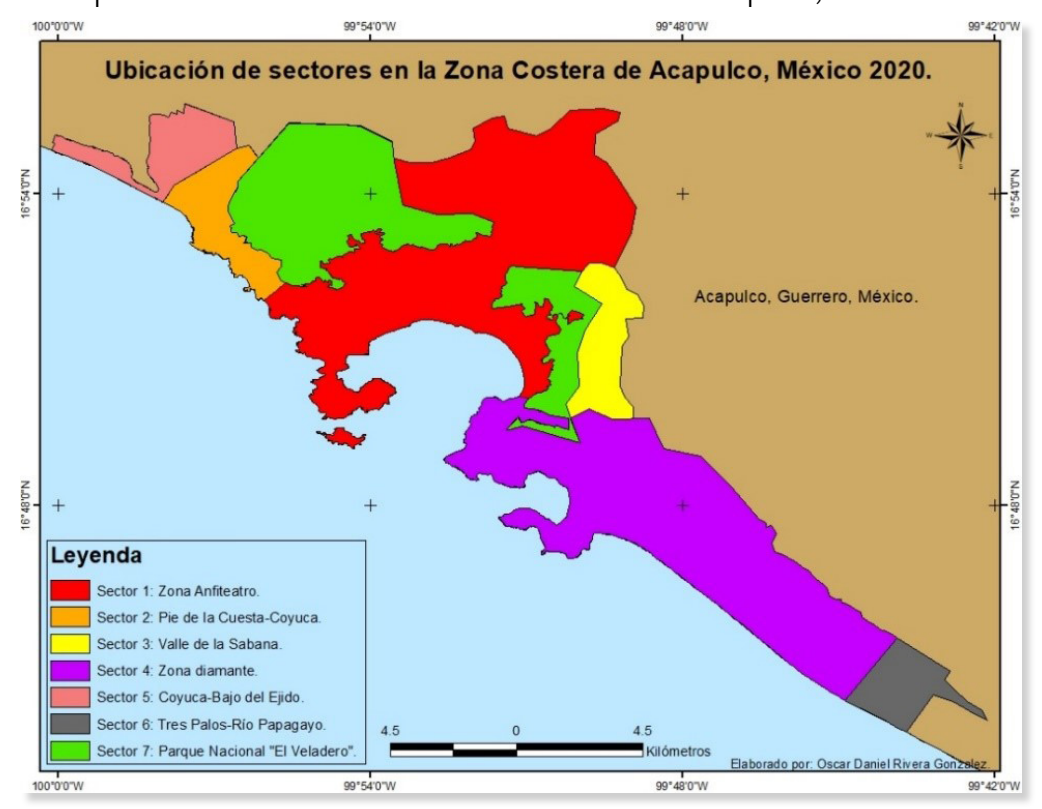

Fuente: elaboración personal con base en datos del Instituto Nacional de Estadística y Geografía (INEGI) y de la Comisión Nacional de Áreas Naturales Protegidas (CONANP), Software SIG ArcMap 10.3

Al inundarse la zona costera específicamente la Avenida Miguel Alemán Valdés y sus alrededores debido a la falta de red de drenaje, ocasiona que residuos fecales terminen en el mar después del paso de la tormenta tropical. Por este motivo la CAPAMA deberá construir y ampliar la red de drenaje sanitario y pluvial en las colonias y zonas antes mencionadas para terminar con la problemática de índole sanitaria en la zona del Anfiteatro. Asimismo, deberá conectar esta nueva red de drenaje a la existente misma que se deberá ampliar, la cual corre a lo largo de la zona costera de Acapulco, mencionando que el drenado final y tratamiento de esta agua residual se explica en las conclusiones.

En Imagen 2 se distingue el funcionamiento del alcantarillado o red de drenaje pluvial, en la cual se observa la precipitación o lluvia, la cual es conducida por medio de canales o tubos para que finalmente termine esta agua drenada en las partes más bajas, mencionando que el Gobierno Municipal de Acapulco o Estatal de Guerrero deberán construir este tipo de drenaje pluvial en zonas al norte de la costera de Acapulco para evitar el colapso de la misma. 


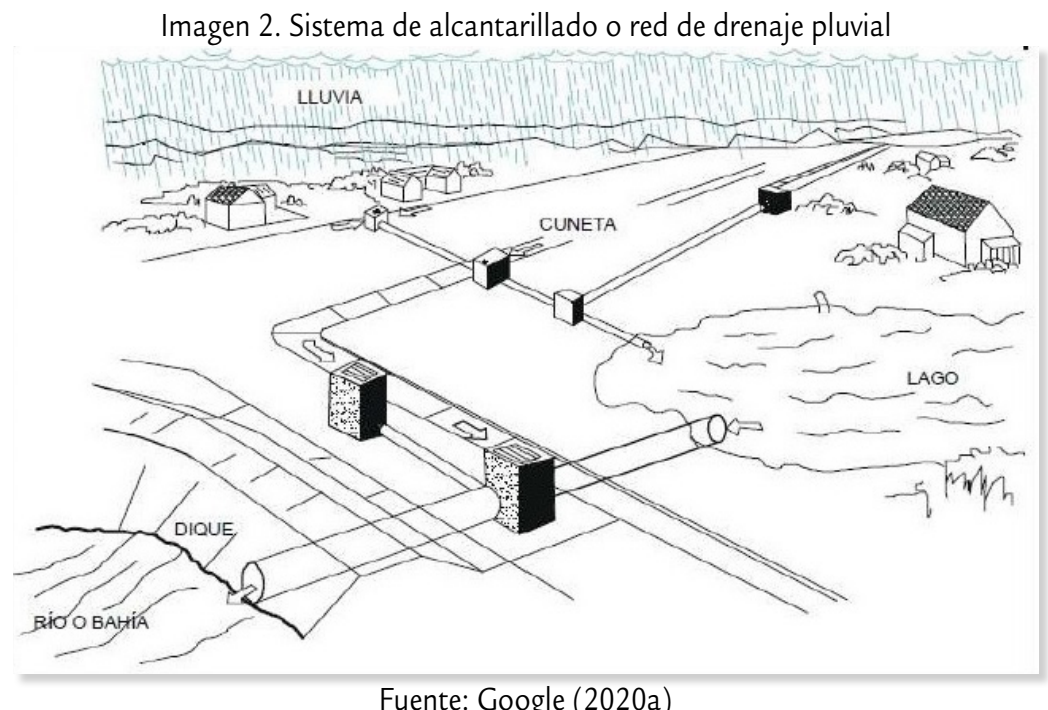

Fuente: Google (2020a)

Complementando la imagen anterior, la Imagen 3 muestra el funcionamiento del alcantarillado o red de drenaje sanitario, el cual va relacionado con el funcionamiento de la red de drenaje pluvial, asimismo con plantas de tratamiento para que esta agua con altos índices de contaminantes no afecten el mar. El Gobierno Municipal de Acapulco o Estatal de Guerrero con apoyo de empresas inmobiliarias deberán construir este tipo de drenaje sanitario en zonas urbanas mismas que cuenten con infraestructura para su construcción, por otra parte las zonas que no cuenten con la infraestructura necesaria por temas de vulnerabilidad económica e índices de marginación se deberá instaurar una red adecuada de drenaje pluvial para aminorar esta problemática.

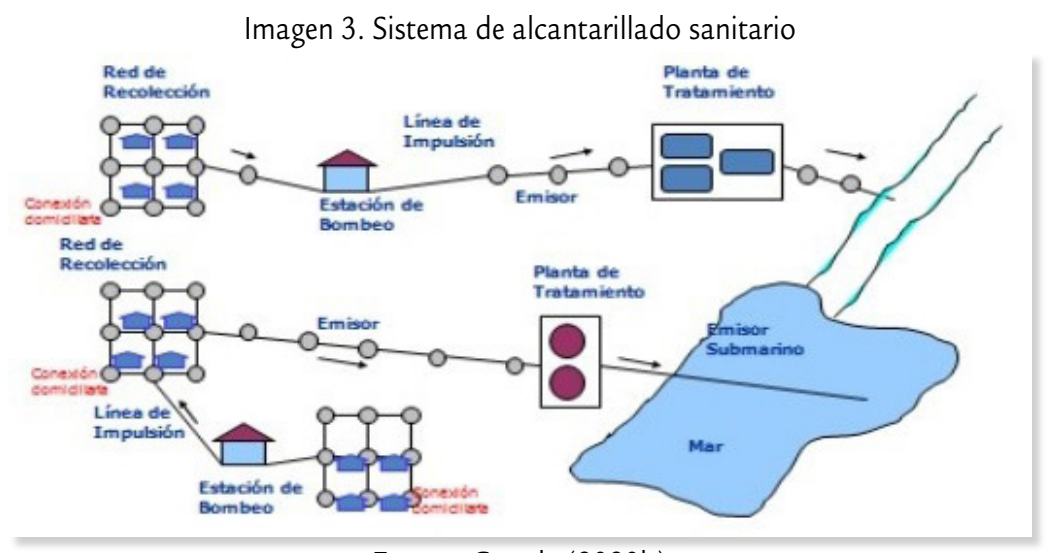

Fuente: Google (2020b)

En el Mapa 8 se observa la extensión y crecimiento urbano por la inadecuada planeación urbana por parte de las autoridades de los tres niveles de Gobierno. Al realizar una comparación de la urbanización en los años 1993 y 2003, se observa el aumento de crecimiento en la parte norte y este de la zona costera de Acapulco derivado de la densidad de población, inclusive en zonas naturales protegidas como lo es el Parque Nacional El Veladero, haciendo caso omiso la autoridad Municipal y Estatal ante la geomorfología, topografía, fisiografía e hidrografía del lugar, los cuales condicionan la habitabilidad de la población. 
Mapa 8. Límite urbano en la zona costera de Acapulco, 1993 y 2003

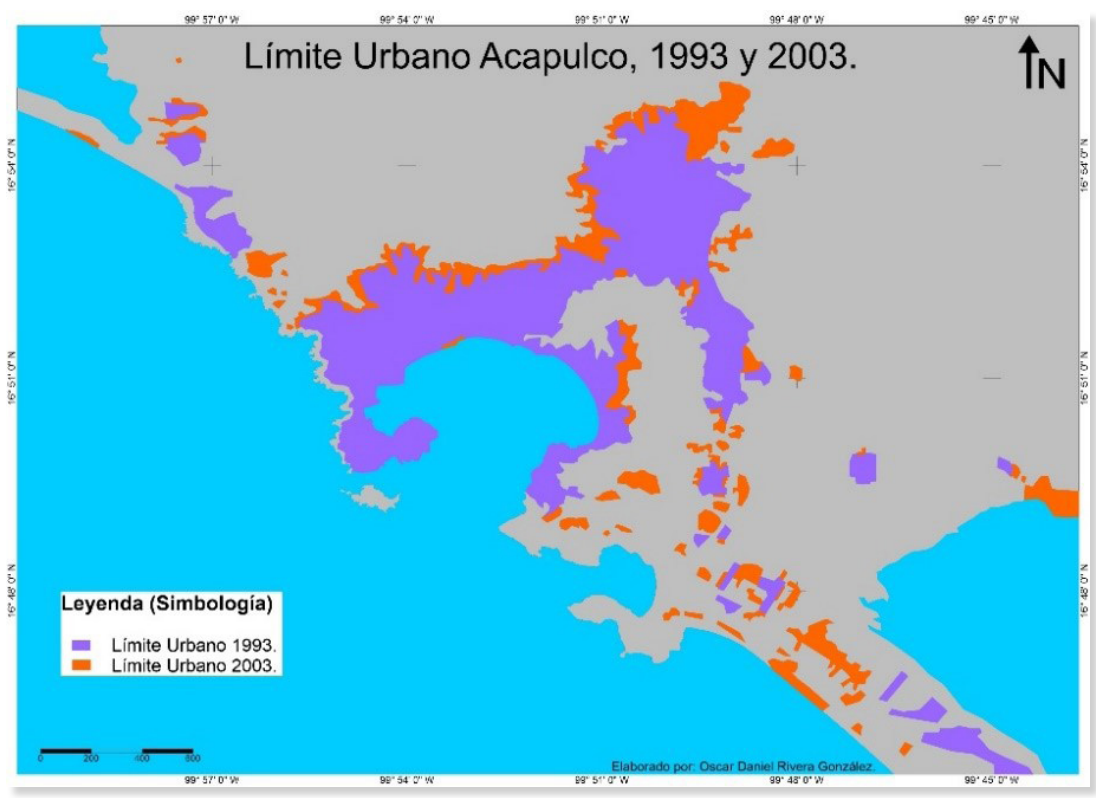

Fuente: elaboración personal con base en datos del Instituto Nacional de Estadística y Geografía (INEGI), Software SIG Surfer 13 y Global Mapper 18

El Mapa 9 complementa al anterior, ya que se distingue el enorme crecimiento urbano en zonas no aptas para la construcción por su composición geomorfológica vulnerable a derrumbes, deslaves, deslizamientos de tierra, inundaciones, entre otros. La mayoría de este crecimiento se sigue dando en la parte norte y este de la zona costera de Acapulco, haciéndola más vulnerable por el grado de inclinación del terreno.

Mapa 9. Límite urbano en la zona costera de Acapulco, 2020

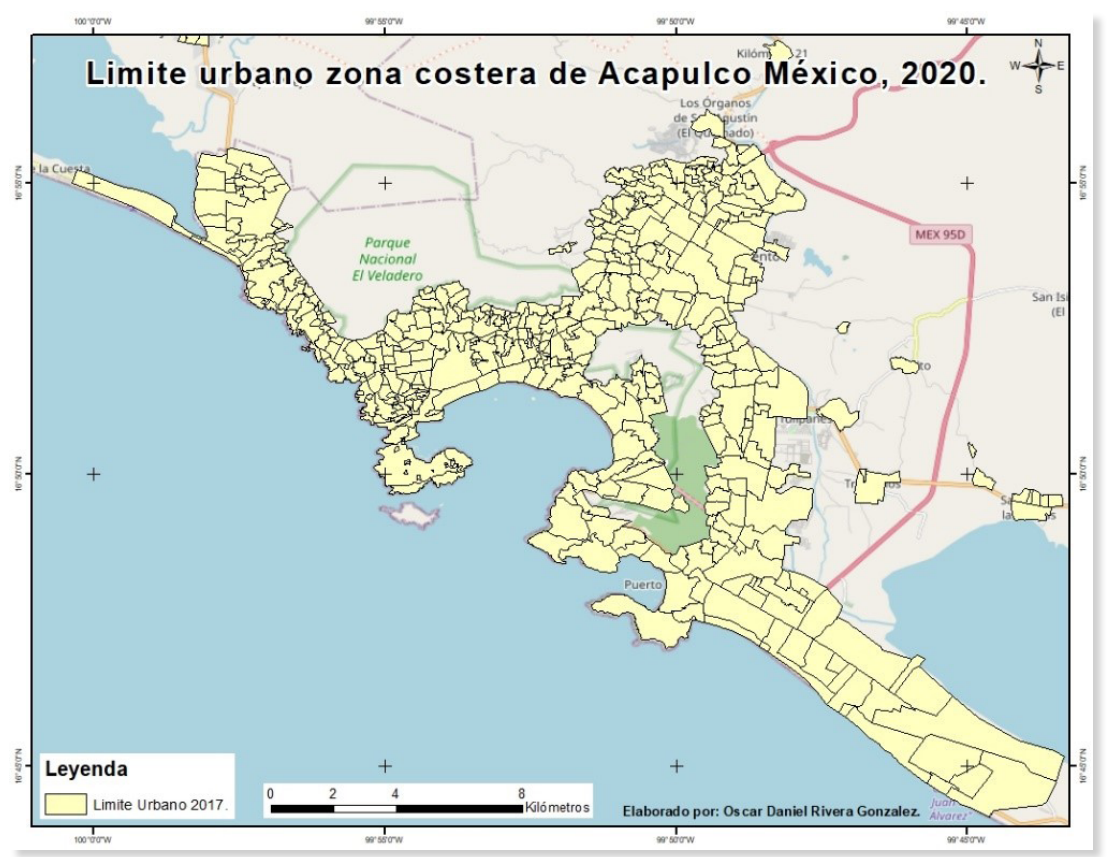

Fuente: elaboración personal con base en datos del Instituto Nacional de Estadística y Geografía (INEGI) e imágenes satelitales, Software SIG ArcMap 10.3 


\section{TÉCNICAS UTILIZADAS}

El crecimiento urbano desregulado se relaciona de alguna manera con cuestiones políticas y toma de decisiones en los tres niveles de Gobierno mencionados anteriormente, lo cual, da como resultado grandes afectaciones urbanas, sociales, ambientales y económicas ante la llegada de un fenómeno hidrometeorológico de tal magnitud, inclusive urbanizando zonas de reserva natural y zonas susceptibles a inundación (colapso de la red de drenaje) y a procesos de remoción en masa (deslaves), observándose el crecimiento urbano en la zona costera de Acapulco y alrededores en los años 1993, 2003 y 2020.

En el Mapa 10 se puede observar, con base en el método utilizado de cálculo de inundación con base en la geomorfología del terreno, el área de inundación de la zona, misma que al retirarse la tormenta tropical Manuel dejó inundaciones horizontales a lo largo de dicha área, la cual según habitantes que han vivido este tipo de acontecimientos va de los 40,50 o 60 metros e inundación vertical de 50 centímetros aproximadamente. Cabe mencionar que no existe información por parte del Gobierno Federal, Estatal o Municipal sobre este tipo de inundación según las mismas autoridades a las que se entrevistaron.

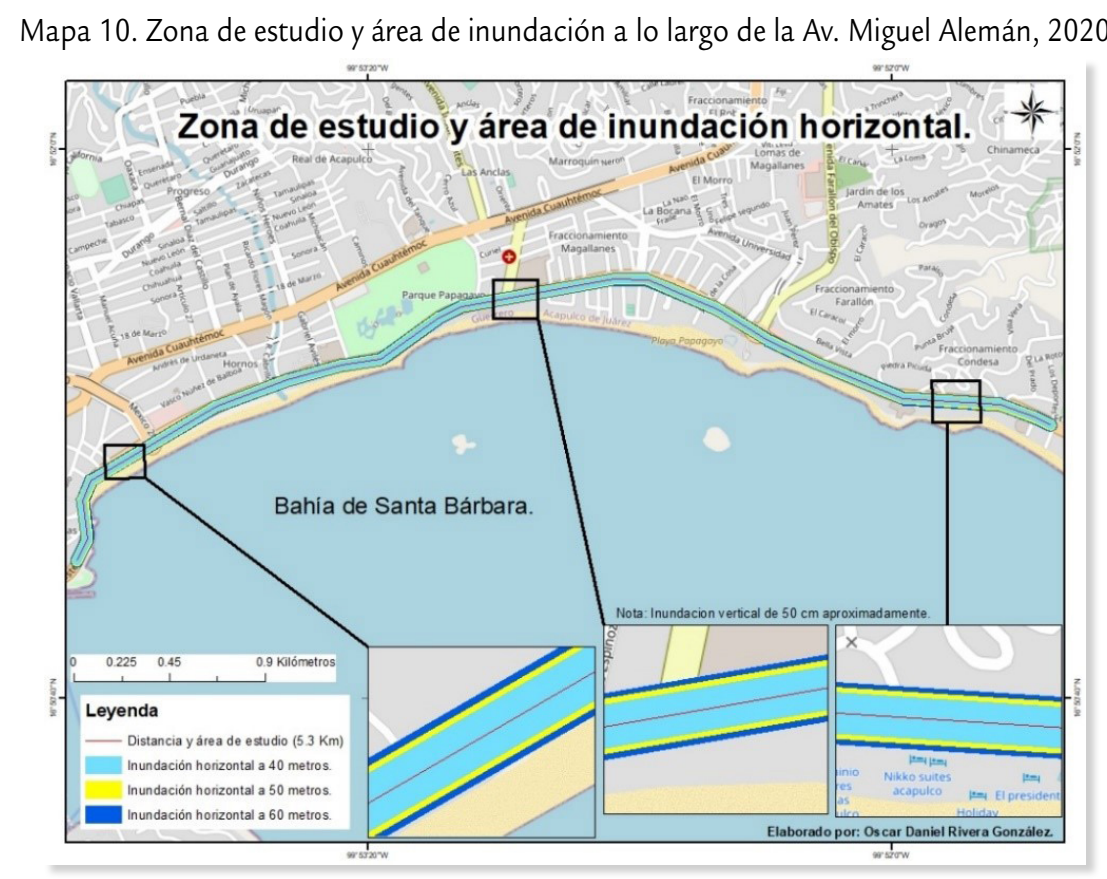

Fuente: elaboración personal con Software SIG ArcMap 10.3

La Imagen 4 complementa al Mapa 10, se distingue la inundación real horizontal y vertical a lo largo de la zona costera de Acapulco después de la tormenta tropical Manuel, inclusive abarca de lado a lado la zona de tránsito de automóviles, afectando de igual manera a comercios formalmente establecidos recordando que toda esta agua se encuentra con algún grado de contaminación, la cual es acarreada finalmente al mar ya sea por trabajadores de la CAPAMA del Municipio de Acapulco o por los mismos habitantes, desencadenando problemáticas posteriores como lo son enfermedades dermatológicas al internarse mar adentro. 


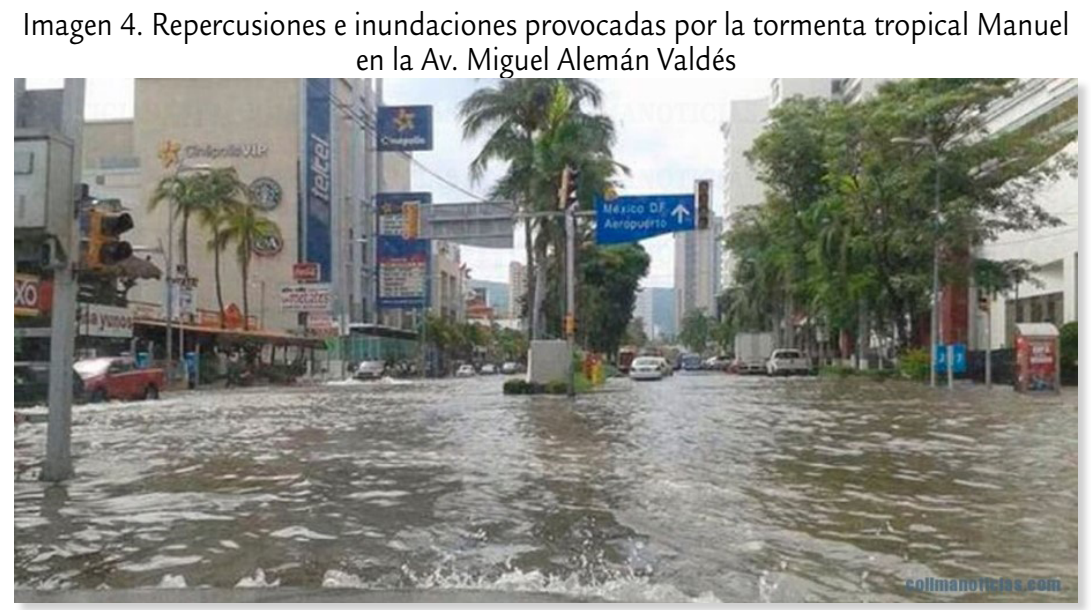

Fuente: Google (2020c)

La Imagen 5 complementa al Mapa 10 y a la Imagen 4, ya que se observa de igual manera la inundación real horizontal y vertical en la Avenida Miguel Alemán Valdés, misma que es paralela a la zona hotelera y a la zona de playa, originándose serias afectaciones al tránsito particular y colectivo, así como a las personas que transitaban peatonalmente el lugar.

Imagen 5. Repercusiones e inundaciones provocadas por la tormenta tropical Manuel en la Av. Miguel Alemán Valdés

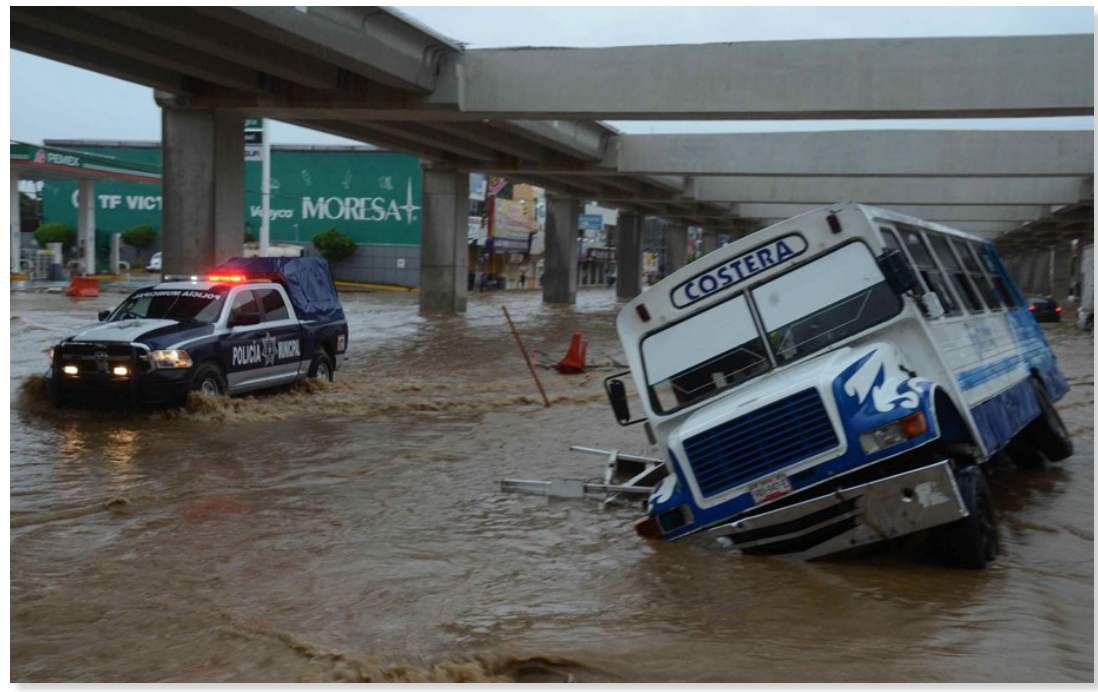

Fuente: Google (2020d)

Aunado a esta problemática se observa que al internarse el huracán tierra adentro como lo fue en el caso de la tormenta tropical Manuel y al presentarse el regreso de agua proveniente del Océano Pacífico dado por la orografía del lugar, aumenta la inundación al llenarse de agua ríos que en la actualidad se encuentran en mayor porcentaje desecados en la parte norte de la costera como lo son: Aguas Blancas, Sub Cuenca Palma Sola-Camarón, Sub Cuenca Magallanes, Sub Cuenca Cañada de los Amates 2, arrasando y elevando su caudal afectando a las poblaciones cercanas (Mapa 11) almacenando agua de mar y colapsando la red de drenaje en las partes más bajas. 
Mapa 11. Zona costera de Acapulco, área de inundación por crecimiento del cauce (hidrografía) y colonias afectadas, 2020

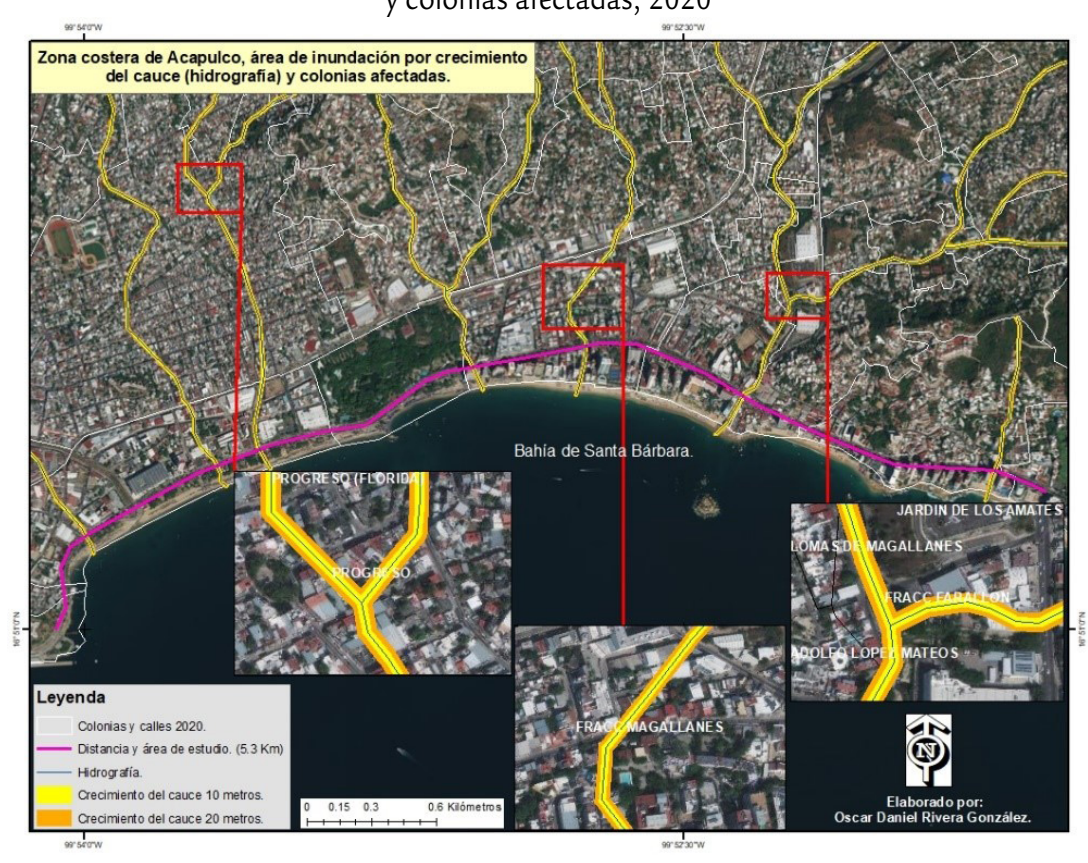

Fuente: elaboración personal con Software SIG ArcMap 10.3

A continuación, se muestra con base en técnicas de análisis de cálculo cuantitativo de crecida de ríos, el mapa del área de inundación horizontal por crecimiento del cauce de la hidrografía al norte de la zona costera de Acapulco, precisando que el grado de inundación aproximadamente de 10 a 20 metros fue estimado con base a la información obtenida de entrevistas a los habitantes del puerto, los cuales han vivido y observado el crecimiento del cauce de los ríos ya que no existe información por parte del Gobierno Federal, Estatal o Municipal (Mapa 11).

Al activarse estos ríos con su flujo y cauce natural, afectan la zona urbanizada específicamente casas y calles, inundando de manera vertical y horizontal zonas urbanas marginadas del puerto de Acapulco, inclusive en la actualidad creciendo dicha urbanización y número de niveles en las construcciones ya existentes debido a la densidad de población, reiterando la desarticulada urbanización dada por los tres niveles de Gobierno, se debió realizar un estudio sobre zonas aptas para la construcción y no realizarlas de manera arbitraria ya que los habitantes del puerto son la población más vulnerable ante estos fenómenos hidrometeorológicos debido a su bajo nivel socioeconómico.

\section{CONCLUSIONES Y RESULTADOS}

La gestión pública urbana otorgada por el Municipio de Acapulco y del Estado de Guerrero es poco eficaz, existiendo ausencia de coordinación entre autoridades gubernamentales con los pobladores afectados y sector privado, lo cual frena cualquier tipo de planeación o gestión pública, afectando directamente a la población antes y después del fenómeno hidrometeorológico creciendo su vulnerabilidad, resultando en el colapso de la red de drenaje a lo largo de la zona costera y alrededores, asociándose diversas problemáticas y consecuencias como: acarreo de sedimentos, inundaciones y fenómenos geomorfológicos como deslizamiento de tierras en la zona del Anfiteatro, misma que es semiurbana y con altos índices de marginación. 
Por otro lado, la inundación llega a los 1, 2 y 3 metros verticalmente a partir de la línea de costa según habitantes ante la llegada de un huracán, interfiriendo en la llegada de servicios médicos y de rescate terrestre, dejando serias afectaciones en la infraestructura urbana, de igual manera el agua contaminada se mezcla con el mar, lo cual, da como resultado enfermedades gastrointestinales y posteriores infecciones dermatológicas para las personas que se internan al mismo.

Una posible solución al colapso de la red de drenaje, será realizar la conexión del drenaje sanitario y pluvial en las partes altas de la zona costera con la parte baja de la deficiente red de drenaje actual que corre a lo largo de la misma, la cual deberá ampliar y dar mantenimiento la CAPAMA. Esta conexión de drenaje permitirá el drenado hacia la parte oeste de dicha zona, específicamente en la colonias Barrio Manzanillo y Ernesto García dado por su composición geomorfológica la cual hará el drenado más sencillo (Mapas 12, 13, 14 e Imagen 6), evitando el regreso de esta agua a la zona costera así como el colapso e inundación. Esta agua contendrá altos índices de contaminación, por lo cual antes del drenado final deberá pasar por algún tipo de planta de tratamiento de agua residual (Imagen 9) para que el mar padezca la menor cantidad de contaminación posible ya que en algún momento esta agua volverá a la costera misma a la que se internan los habitantes y turistas.

Otra alternativa de drenado es la misma construcción de la red de drenaje sanitario y pluvial sin conexión entre la parte norte y sur (Mapa 15), asimismo la construcción de cámaras o cajas rompe presión (Imagen 8) y la construcción de cinco plantas de tratamiento de agua residual, mencionando que el drenado del agua sería por la parte oeste de la zona costera de Acapulco específicamente en las colonias y puntos de sur a norte, Juan N. Álvarez, Fracc. Residencial Mozimba, Fracc. Punta Gorda, Vista Azul y Balcones al Mar (Mapa 15).

Con base en la explicación anterior, se detalla la instauración de cada una de las posibles soluciones para una mejor comprensión.

El Mapa 12 muestra una primera proyección de la posible construcción de la red de drenaje, asimismo la conexión de la parte norte de la zona costera (zona Anfiteatro) con partes bajas de la misma, realizando estos cálculos con base en imágenes satelitales, ortofotos e imágenes raster determinando la hidrografía y geomorfología de la zona, cabe mencionar que la posible construcción de cámaras rompe presión será de 75 a lo largo de la red de drenaje y una planta de tratamiento de agua residual con base a los vértices obtenidos en el mapa y geomorfología del lugar.

Por otra parte se muestra una segunda proyección de la posible construcción de la red de drenaje (Mapa 13), asimismo la conexión de la parte norte de la zona costera (zona Anfiteatro) con partes bajas de la misma, realizando estos cálculos con base en imágenes satelitales e imágenes tipo raster, la construcción de cámaras rompe presión será de 66 a lo largo de la red de drenaje y una planta de tratamiento de agua residual según los vértices y geomorfología.

En el Mapa 14 se muestra la dirección del posible drenado y construcción de la planta de tratamiento de aguas residuales en caso de inundación, que deberá ser construida por la CAPAMA mejorando la deficiente red de drenaje que se encuentra en la actualidad en la parte norte de la zona costera y sobre esta misma con base a la geomorfología, orografía y topografía del lugar, para aminorar o posiblemente desaparecer el colapso de la red de drenaje y así la zona urbana sea menos vulnerable después de algún fenómeno hidrometeorológico. 
Mapa 12. Primera posible construcción de red de drenaje para evitar el colapso de la misma, Acapulco, 2020

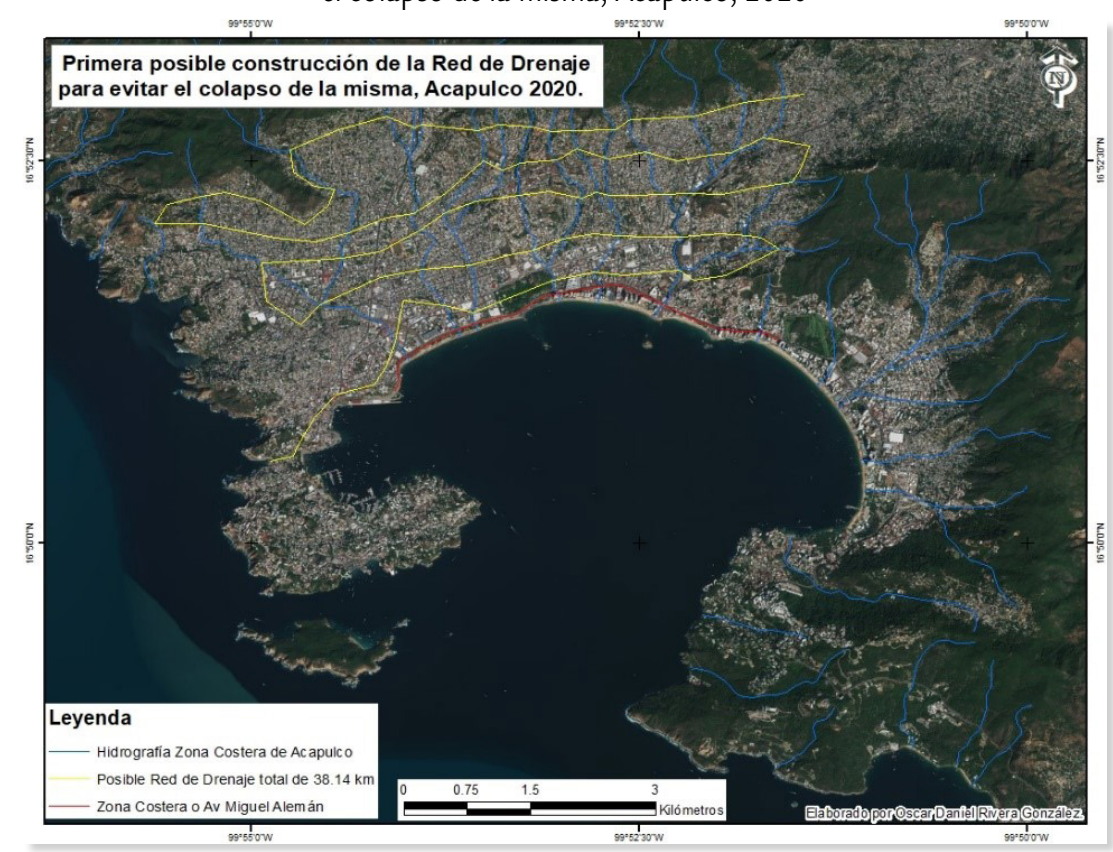

Fuente: elaboración personal con Software SIG ArcMap 10.3

Mapa 13. Segunda posible construcción de red de drenaje para evitar el colapso de la misma, Acapulco, 2020

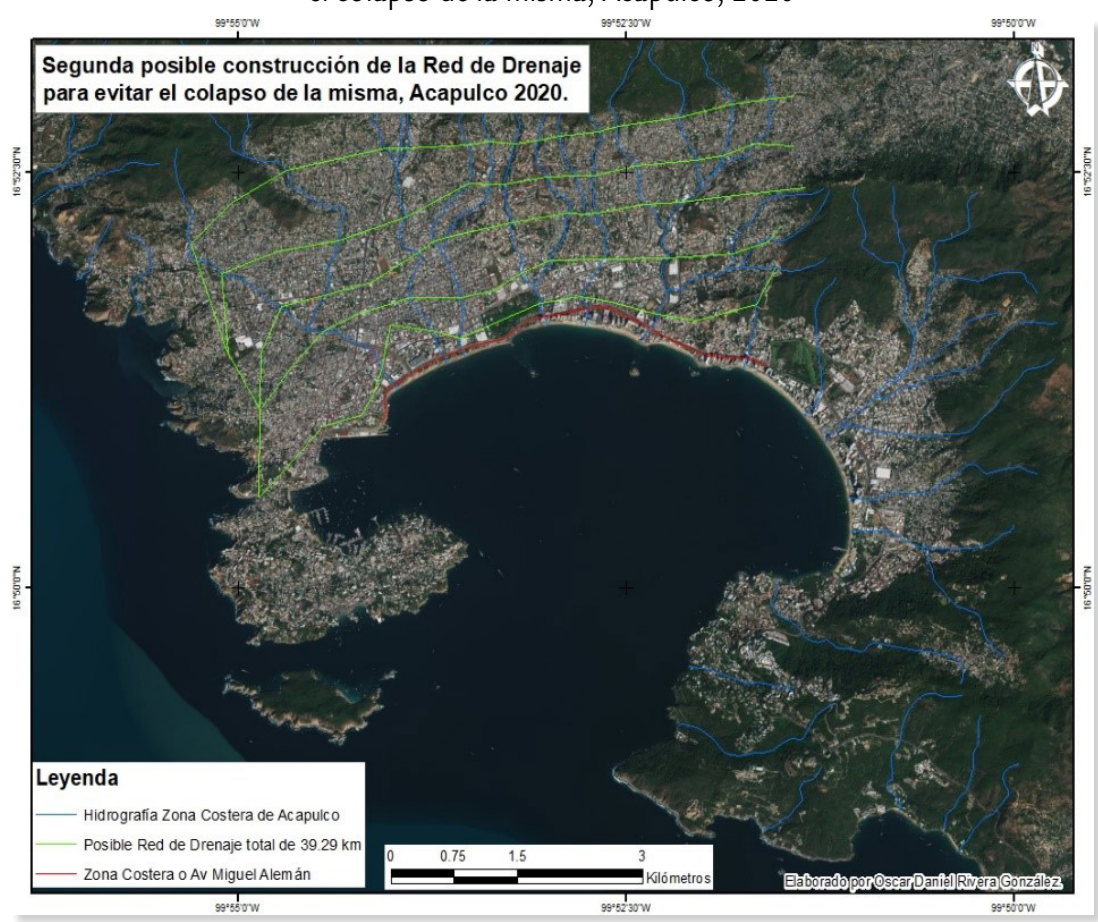

Fuente. Elaboración personal con Software SIG ArcMap 10.3 
Mapa 14. Dirección y área del posible drenado ante la llegada de fenómenos hidrometeorológicos para evitar el colapso de la red de drenaje en la zona costera de Acapulco, 2020

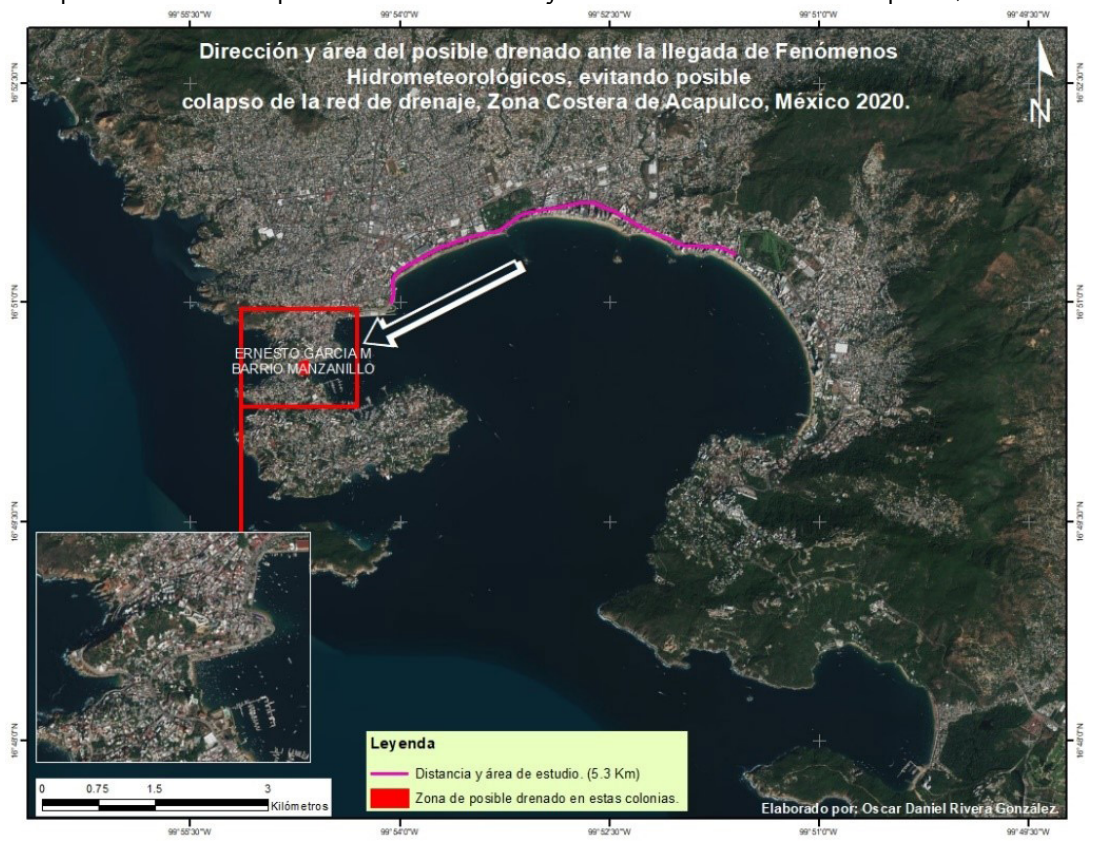

Fuente: elaboración personal con Software SIG ArcMap 10.3

La Imagen 6 complementa el mapa anterior. Se distingue el corte de terreno de dirección este a oeste de la zona costera de Acapulco, por lo que con este perfil del terreno queda más clara la altura en m.s.n.m de la posible área de drenado en caso de colapso de la red de drenaje, su límite geomorfológico más alto es de 214 metros, al ser relativamente bajo en comparación con otras zonas en la costera de Acapulco para el drenado del agua, este límite geomorfológico no permitirá el regreso del agua de mar a la zona costera.

Imagen 6. Perfil del terreno zona oeste en la costera de Acapulco, imagen raster 3D (línea amarilla de este a oeste) y perfil del terreno representado en metros (gráfica línea roja de izquierda a derecha)
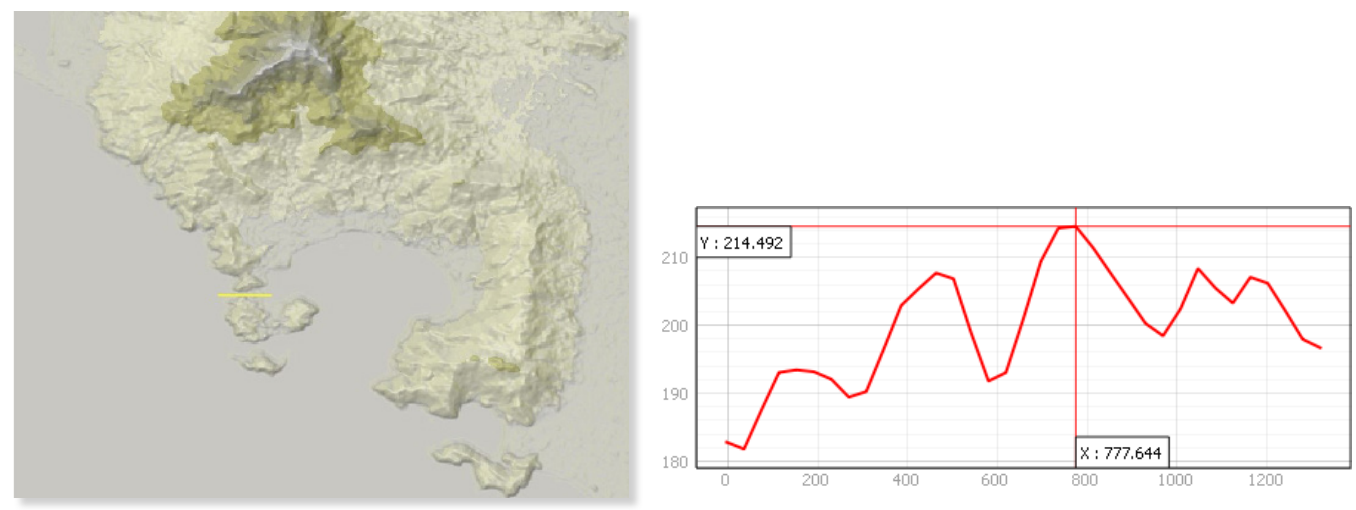

Fuente: elaboración personal con Software SIG QGIS 2.18.12

El Mapa 15 muestra una tercera proyección de la posible construcción de red de drenaje sin conexión entre la parte norte de la zona costera (zona Anfiteatro) y la partes bajas de la misma, realizando estos cálculos con base en imágenes satelitales, ortofotos e imágenes raster determinando la hidrografía y geomorfología de la zona, cabe mencionar que la posible construcción de cámaras rompe presión será de 74 a lo largo de 
la red de drenaje y cinco plantas de tratamiento de agua residual, mencionando que el drenado del agua sería por la parte oeste de la zona costera de Acapulco específicamente en las colonias y puntos de sur a norte, Juan N. Álvarez, Fracc. Residencial Mozimba, Fracc. Punta Gorda, Vista Azul y Balcones al Mar, con base a los vértices obtenidos en el mapa y geomorfología del lugar.

Mapa 15. Tercera posible construcción de red de drenaje para evitar el colapso de la misma, Acapulco, 2020

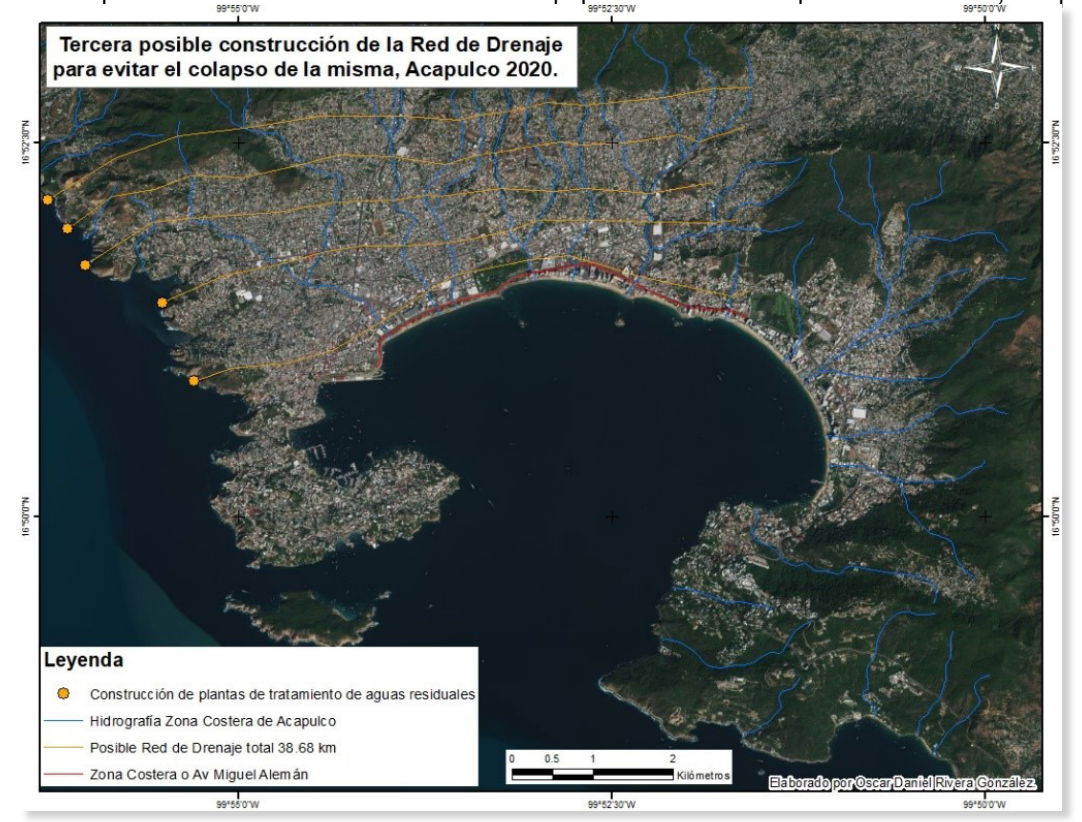

Fuente: elaboración personal con Software SIG ArcMap 10.3

La Imagen 7 complementa el Mapa 15. Se distingue el corte del terreno de dirección sur a norte de la zona costera de Acapulco, por lo que con este perfil del terreno queda más clara la altura en metros de la posible área de drenado en caso de colapso de la red de drenaje, su límite geomorfológico más alto es de 199 metros, al ser relativamente bajo en comparación con otras zonas en la costera de Acapulco para el drenado del agua, este límite geomorfológico no permitirá el regreso del agua de mar a la zona costera de Acapulco, sin embargo, se tendrán que construiry dar mantenimiento a cinco plantas de tratamiento de agua residual.

Imagen 7. Perfil del terreno zona oeste en la costera de Acapulco, imagen raster 3D (línea amarilla de Sur a Norte) y perfil del terreno representado en metros (gráfica línea roja de izquierda a derecha)

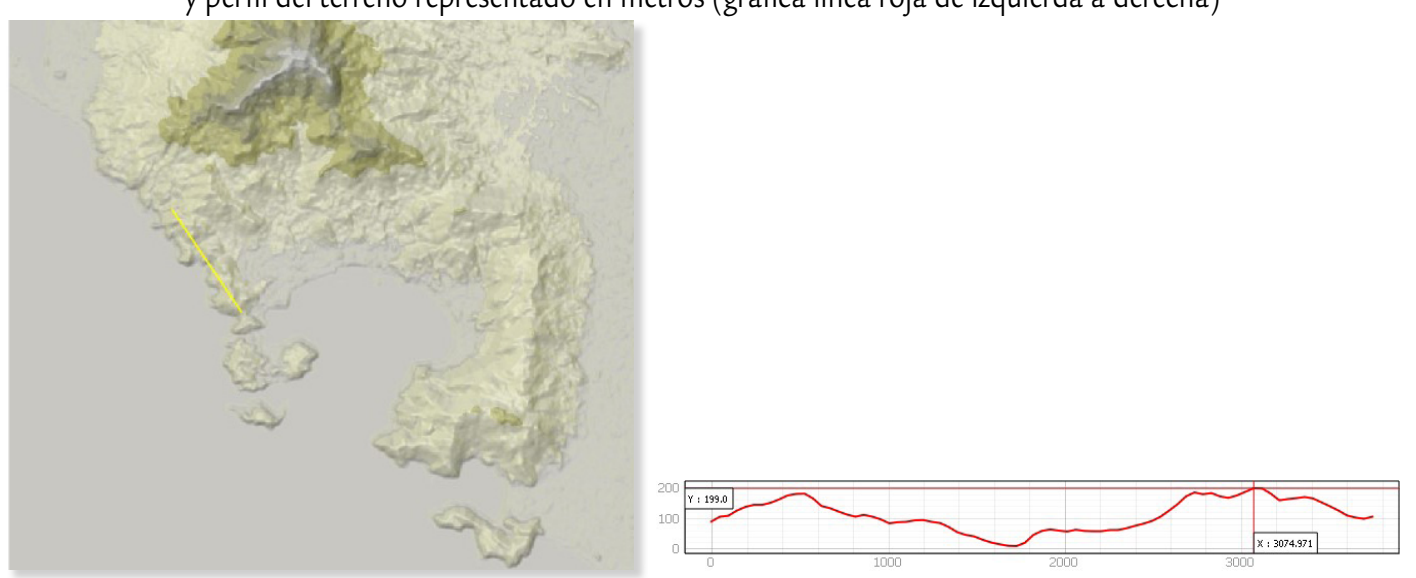

Fuente: elaboración personal con Software SIG QGIS 2.18.12. 
En la Imagen 8 se observan las partes internas de la caja o cámara rompe presión, las cuales deberán ser instauradas a lo largo de la red de drenaje pluvial para aminorar la caída y presión dada ante lluvias extraordinarias originadas por impacto de fenómenos hidrometeorológicos, las cuales deberán ser construidas por la CAPAMA, precisando que este es un tema de ingeniería, el cual el autor de este articulo solo lo propone como una alternativa ante el colapso de la red de drenaje en la zona costera de Acapulco.

En la Imagen 9 se observa la posible construcción y conclusión de plantas de tratamiento de aguas residuales en la zonas y colonias antes mencionadas dado por la geomorfología del lugar, para el drenado ante la llegada de fenómenos hidrometeorológicos, mencionando de igual manera que este es un tema de ingeniería el cual el autor de este articulo solo lo propone como una alternativa ante el colapso de la red de drenaje en la zona costera de Acapulco.

Imagen 8. Partes internas de la cámara rompe presión

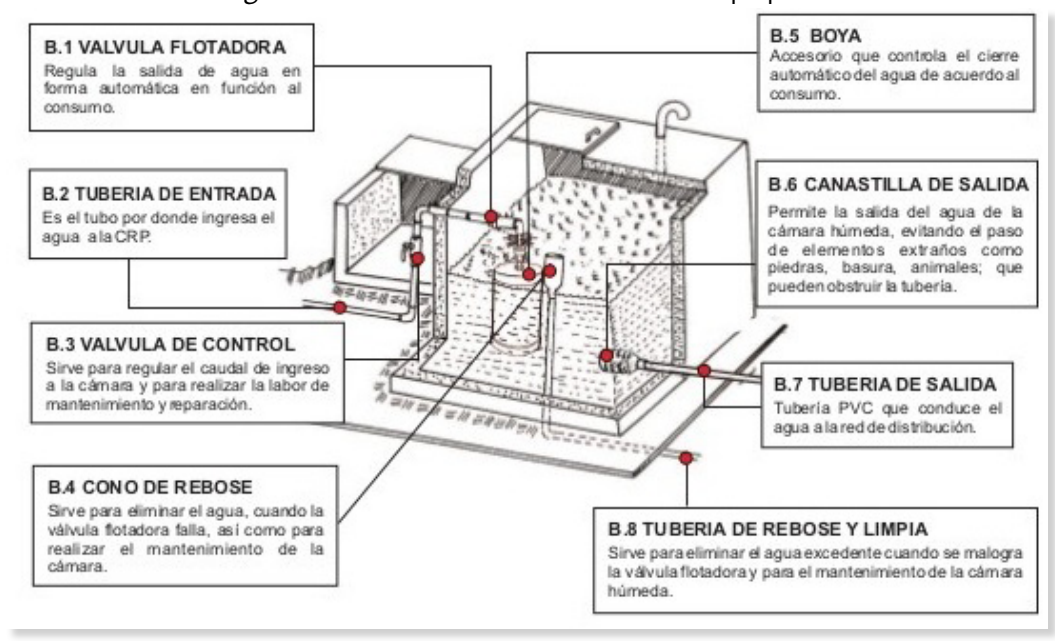

Fuente: Google (2020e)

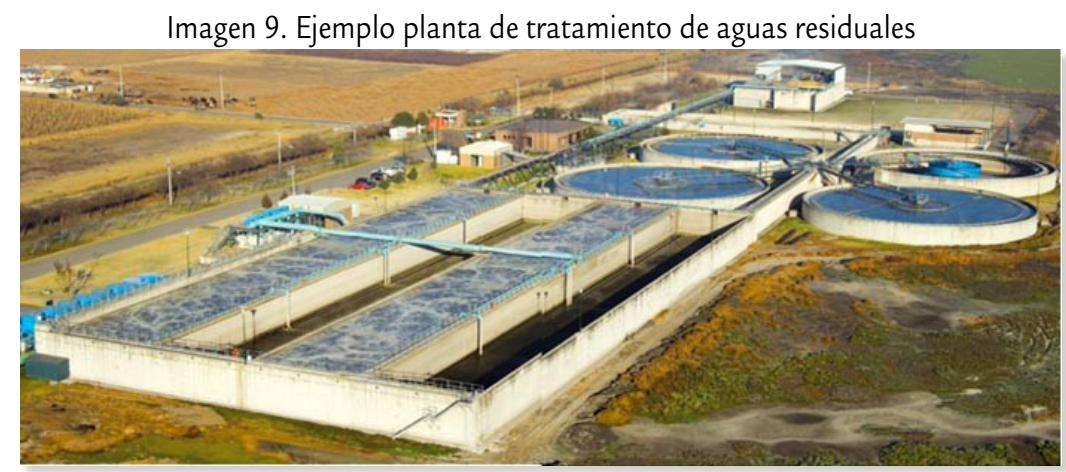

Fuente: Google (2020f)

\section{REFLEXIÓN}

La gestión pública en México en su mayoría es poco efectiva, se observa en muchos aspectos y específicamente en la toma de decisiones por parte de las autoridades ya sea a nivel Federal, Estatal, Municipal, mismas que al no ejecutar una decisión adecuada en cuanto a la gestión pública urbana con base en una política de mantenimiento y prevención, afectarán aún más a las zonas vulnerables ambientalmente, socialmente, económicamente, políticamente, por lo cual, resulta muy complicado resarcir cualquier tipo de daño asociado a huracanes. 
De no poner un alto o dar solución real, crecerá y agravará aún más la problemática acontecida año con año en la zona costera de Acapulco. Se deberá trabajar y auditar a las instituciones públicas encargadas de la protección a los habitantes en temporada de huracanes, por lo que con base en los resultados obtenidos en los mapas finales, se observa que existe una solución real a dicha situación, inclusive posterior a la posible construcción de drenado e instauración de cámaras rompe presión para la solución al colapso de la red de drenaje, podrá ser mejorado y reforzado con una adecuada gestión social del riesgo, con base en la coordinación entre las autoridades en cualquiera de sus tres niveles de gobierno en México con la población posiblemente afectada y sector privado el cual también sufre de afectaciones en diferente proporción, lo cual, permitirá generar medidas de gestión, comunicación, concertación, para minimizar o posiblemente desaparecer el impacto de Huracanes y salvaguardar a la población más necesitada.

Por último, es importante precisar que dicha instauración de drenado podrá ser posible adaptarlo en otras zonas costeras de México, ya que dichos fenómenos hidrometeorológicos impactan en la parte del Golfo de México y el Océano Pacifico cada año, inclusive aplicarlo en otras latitudes en el mundo que cuenten con características geográficas, geomorfológicas, hidrográficas, geológicas, edafológicas, similares a la zona de estudio.

\section{REFERENCIAS}

Enfoque (2013). Riesgo de Colapsar Avenida Miguel Alemán. Editorial Periódico Enfoque. Acapulco, Guerrero México. Recuperado de http://enfoqueinformativo.mx/nuevo/index.php/local/item/8387-riesgo-de-colapsar

ERN (2013). Daños por los huracanes Ingrid y Manuel. México: ENRtérate.

Expansión (2013). Tormenta Manuel deja incomunicado a Acapulco. Editorial Periódico Expansión. Ciudad de México, México. Recuperado de http://expansion.mx/nacional/2013/09/16/la-tormenta-manuel-deja-incomunicado-al-puerto-de-acapulco

Fariña, J.; Fernández, V.; Gálvez, M.; Hernández, A. y Urrutia, N. (2013). Manual de Diseño Bioclimático Urbano. Lisboa, Portugal: Editorial Instituto Politécnico de Bragança.

Harvey D. (2003). Espacios del Capital. Madrid España: Editorial Akal.

Ramírez Sainz, J. (1989). Turismo y Medio Ambiente: El caso de Acapulco. Ciudad de México, México: Editorial Universidad Autónoma Metropolitana.

Rodríguez Esteves J. (2017). Los desastres recurrentes en México: El huracán Pauline y la tormenta Manuel en Acapulco, Guerrero. Editorial Anuario Electrónico de Estudios en Comunicación Social Disertaciones, 10(2). Recuperado de https://www.redalyc.org/jatsRepo/5115/511552609009/511552609009.pdf

Servicio Meteorológico Nacional SMN (2013). Huracán Manuel. Ciudad de México, México: Editorial SMN. Recuperado de http://smn.cna.gob.mx/tools/DATA/Ciclones\%20 Tropicales/Ciclones/2013-Manuel.pdf.

Wilches Chaux, G. (1993). La vulnerabilidad global. Editorial Red de Estudios Sociales en Prevención de Desastres en América Latina. Puerto Limón Costa Rica.

\section{FUENTES DE INTERNET}

Google (2020a). México. Recuperado de https://www.google.com.mx/search?q=re$d+d e+d r e n a j e+p l u v i a \mid \& s a=X \& t b m=i s c h \& i m g i l=H J 2 C Q i L p 9 y 9 K G M \% 253 A \% 253 B G-$ 
TPnBjVq-\&ei=9YCpWc2zF4LMmwGnnrawBg\#imgrc=HJ2CQiLp9y9KGM

Google (2020b). México. Recuperado de https://www.google.com.mx/search?q=red+de + drenaje+sanitario\&source $=$ Inms\&tbm $=$ isch\&sa $=X \& v e d=0$ ahUKEwiewvS2qoTWAhVOfiYKHXBfDwwQ_AUICigB\&biw=1536\&bih=759\#imgrc=zqKNX7R535gpHM

Google (2020c). México. Recuperado de https://www.google.com.mx/search?q=inundacion+av+miguel+aleman+acapulco\&source $=$ Inms\&tbm $=$ isch\&sa $=X \& v e d=0$ ahUKEwid2Oid7pDUAhXM5oMKHZukBV0Q_AUICigB\&biw=1366\&bih=662\#imgrc=R6EYyCGiSX

Google (2020d). México. Recuperado de https://www.google.com.mx/search?q=inundaciones $+y+$ fecalismo + en + acapulco\&espv $=2 \& b i w=1920 \& b i h=889 \&$ source $=$ Inms \&tb$\mathrm{m}=\mathrm{isch} \& \mathrm{sa}=\mathrm{X} \&$ ved $=0 \mathrm{ahU}$

Google (2020e). México. Recuperado de https://www.google.com.mx/search?q=cajas+rompepresion\&tbm $=$ isch\&tbo $=u \&$ source $=u n i v \& s a=X \& v e d=0$ ahUKEwij_Myg2ITWAhUU32MKHQliCfcQsAQIJQ\&biw=1536\&bih=759\#imgrc=_br1afanz888uM

Google (2020f). México. Recuperado de https://www.google.com.mx/search?$q=$ plantas+tratadoras + de + aguas + residuales \&source $=\operatorname{lnms} \& t b m=i s c h \& s a=X \& v e-$ $\mathrm{d}=$ 0ahUKEwjjrKCbroTWAhVolVQKHbnHBeAQ_AUICigB\&biw=1536\&bih=759\#imgr$\mathrm{c}=$ KQDRYPVOrsOi1M

SoftWARES utilizados (Sistemas de InFormación Geográfica)

SIG ArcMap 10.3

SIG Global Mapper 18

SIG gvSIG.2.1.0.2269.

SIG Maplnfo Pro 15.2

SIG QGIS 2.18.12.

SIG Surfer 13.

Oscar Daniel Rivera González es Licenciado en Geografía por la Universidad Nacional Autónoma de México UNAM (2007); número de cedula profesional Secretaria de Educación Pública (SEP): 7189460. Especialista en Economía ambiental y Ecológica Universidad Nacional Autónoma de México UNAM (2014); número de cedula profesional Secretaria de Educación Pública (SEP): 9262459. Maestro en Urbanismo Universidad Nacional Autónoma de México UNAM (2017); número de cedula profesional Secretaria de Educación Pública (SEP): 10868790. Desde el año 2018 estudiante de Doctorado en Urbanismo (4 semestre) Universidad Nacional Autónoma de México UNAM. Trabajando en diferentes artículos científicos en las áreas de interés: fenómenos hidrometeorológicos e inundaciones y sus afectaciones en zona urbanas en México; fenómenos geomorfológicos, geológicos, hidrológicos, edafológicos y afectaciones en zonas urbanas en México; deslizamientos de tierra/inestabilidad de laderas/procesos de remoción en masa implementados en modelos de prevención y predicción real en México y el mundo, afectaciones económicas después del impacto de fenómenos naturales en zonas costeras en México, entre otros. Actualmente trabajando en la tesis doctoral titulada: Gestión integral del riesgo en zonas urbanas marginadas vulnerables a procesos de remoción en masa, zona norte alcaldía Álvaro Obregón, 2014-2019. Facultad de Arquitectura. Universidad Nacional Autónoma de México (UNAM). Circuito de los Posgrados S/N, C.U., Coyoacán, 04510 Ciudad de México, CDMX, México, oscardanieldanyboy@hotmail.com, ORCID https://orcid.org/0000-0002-7698-7433 